\title{
A Highly Fluorescent Dinuclear Aluminium Complex with Near-Unity Quantum Yield
}

\author{
Flavio L. Portwich,, ${ }^{[a]}$ Yves Carstensen, ${ }^{[b]}$ Anindita Dasgupta, ${ }^{[c, d]}$ Stephan Kupfer, ${ }^{[b]}$ Ralf \\ Wyrwa, ${ }^{[e]}$ Helmar Görls, ${ }^{[a]}$ Christian Eggeling, ${ }^{[c, d, f, g, h]}$ Benjamin Dietzek, ${ }^{[b, c, f, h]}$ Stefanie

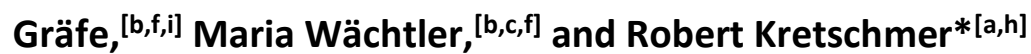

Dedicated to Heinrich Lang on the occasion of his $65^{\text {th }}$ birthday.

\begin{abstract}
The high natural abundance of aluminium makes the respective fluorophores attractive for various optical applications, but photoluminescence quantum yields above 0.7 have yet not been reported for solutions of aluminium complexes. In this contribution, a dinuclear aluminium(III) complex featuring enhanced photoluminescence properties is described. Its facile one-pot synthesis originates from a readily available precursor and trimethyl aluminium. In solution, the complex exhibits an unprecedented photoluminescence quantum yield near unity $\left(\Phi_{\text {absolute }} 1.0 \pm 0.1\right)$ and an excited-state lifetime of $2.3 \mathrm{~ns}$. In the solid state, J-aggregation and aggregation-caused quenching are noticed, but still quantum yields of 0.6 are observed. Embedding the complex in electrospun nonwoven fabrics yields a highly fluorescent fleece possessing a quantum yield of $0.9 \pm 0.04$.
\end{abstract}

[a] F. L. Portwich, Dr. H. Görls, Prof. Dr. R. Kretschmer, Institute of Inorganic and Analytical Chemistry (IAAC), Friedrich Schiller University Jena, Humboldtstraße 8, 07743 Jena, Germany, robert.kretschmer@uni-jena.de

[b] Y. Carstensen, Dr. S. Kupfer, Prof. Dr. B. Dietzek, Prof. Dr. S. Gräfe, Dr. M. Wächtler, Institute of Physical Chemistry Friedrich Schiller University Jena, Helmholtzweg 4, 07743 Jena, Germany [c] A. Dasgupta, Prof. Dr. C. Eggeling, Prof. Dr. B. Dietzek, Dr. M. Wächtler, Leibniz Institute of Photonic Technology, Albert-Einstein-Straße 9, 07745 Jena, Germany

[d] A. Dasgupta, Prof. Dr. C. Eggeling, Institute of Applied Optics and Biophysics, Friedrich Schiller University Jena, Helmholtzweg 4, 07743 Jena, Germany

[e] Dr. R. Wyrwa, INNOVENT e. V. Technologieentwicklung Jena, Prüssingstraße 27 B, 07745 Jena, Germany

[f] Prof. Dr. C. Eggeling, Prof. Dr. B. Dietzek, Prof. Dr. S. Gräfe, Dr. M. Wächtler, Abbe Center of Photonics, Friedrich Schiller University Jena, Albert-Einstein-Straße 6, 07745 Jena, Germany

[g] Prof. Dr. C. Eggeling, MRC Human Immunology Unit, Weatherall Institute of Molecular Medicine, University of Oxford, OX39DS Oxford, UK

[h] Prof. Dr. C. Eggeling, Prof. Dr. B. Dietzek, Prof. Dr. R. Kretschmer, Jena Center for Soft Matter (JCSM), Friedrich Schiller University Jena, Philosophenweg 7, 07743 Jena, Germany

[i] Prof. Dr. S. Gräfe, Fraunhofer Institute for Applied Optics and Precision Engineering (Fraunhofer IOF) Albert-Einstein-Str. 7, 07745 Jena, Germany 


\section{Introduction}

Fluorescent compounds based on main-group elements are of fundamental interest as they combine favorable electrochemical, photophysical, and spectroscopic properties with the high natural abundance of many of the s- and p-block elements. Therefore, related fluorophores have found numerous applications for example in bioimaging, ${ }^{1}$ chemosensing ${ }^{1 b, 2}$ or as materials for organic light-emitting diodes (OLEDs). ${ }^{3}$ However, although many of the main-group elements are more abundant than $2^{\text {nd }}$ and $3^{\text {rd }}$ row transition metals, the supply of certain elements such as boron, germanium and bismuth is at (future) risk. $^{4}$ In light of the broad applications of boron-containing dyes like BODIPY and derivatives, ${ }^{10,5}$ developing fluorophores based on its non-endangered relative aluminium is a highly desirable task. In the late 1980s, tris(8-hydroxyquinolinato)aluminium(III) (Alq3) has been used to develop the first thin-film light-emitting diode, ${ }^{6}$ wherefore the development of aluminium complexes with improved emission efficiencies received considerable interest. While at the beginning, most of the studies were focused on modifications of the 8-hydroxyquinoline ligands, ${ }^{3 e, 7}$ the last decade has witnessed the development of new aluminium-containing fluorophores with improved photophysical properties. ${ }^{8}$ But although the photoluminescence quantum yields in solution have been significantly improved from 0.2 in case of Alq $3^{9}$ up to 0.7 for an aluminium $\mathrm{N}_{2} \mathrm{O}_{2}$-dipyrrin complex, ${ }^{8 \mathrm{~b}}$ they still cannot compete with dyes based on their lighter or heavier group 13 relatives such as BODIPY ${ }^{10}$ or GADIPY ${ }^{11}$, Figure 1, possessing quantum yields (in toluene) of 0.8 and 0.9 , respectively. In this contribution, we present a readily available dinuclear aluminium(III) complex (1) possessing an unprecedented photoluminescence quantum yield up to 1.0 in solution, which adds information to the yet under-explored photochemistry of dinuclear complexes. ${ }^{12}$

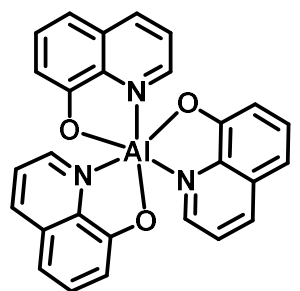

Alq3

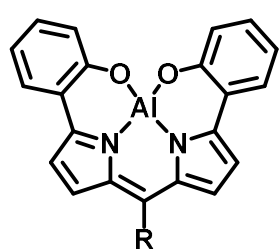

Al $\mathrm{N}_{2} \mathrm{O}_{2}$-dipyrrin

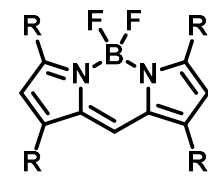

BODIPY

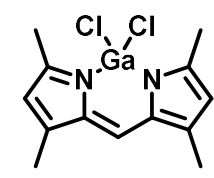

GADIPY

Figure 1. Selected structures of group 13 dyes. 


\section{Discussion}

Complex $\mathbf{1}$ is conveniently prepared in good yield from the $\beta$-oxo- $\delta$-diimine (BODDI) $\mathbf{H}_{2}{ }^{13}$ and trimethylaluminium, Scheme 1. Its molecular structure in the solid state, Figure 2, resembles structural features of previously reported $\beta$-oxo- $\delta$-diimine complexes of lutetium and zinc: ${ }^{13 a, 14}$ the two tetrahedral coordinated aluminium centers are chelated in a $\mathrm{K}^{1}-\mathrm{N}: \mu^{2}-\mathrm{O}: \mathrm{K}^{1}-$ $\mathrm{N}$ fashion and reside on opposite sites and $0.74 \AA$ above the almost planar BODDI backbone. The $\mathrm{Al}-\mathrm{C}, \mathrm{Al}-\mathrm{N}$, and $\mathrm{Al}-\mathrm{O}$ bond lengths are in good agreement with related dinuclear complexes based on N,O-chelating ligands. ${ }^{15}$ The packing of $\mathbf{1}$ in the crystal structure, Figures S1-S3, is strongly affected by the steric demands of the 2,6-diisopropylphenyl (Dipp) groups, which is why neither dispersive intermolecular interactions between the $\pi$-systems nor any well-defined interaction with the backbone of the BODDI ligand is observed. The molecules are packed into two-dimensional sheets and the molecules of two adjacent layers are facing each other. A simple set of ${ }^{1} \mathrm{H}$ NMR resonances of the Dipp groups (two methyl doublets and one methine septet), of the BODDI-backbone (one methyl and one methine singlet), and the $\mathrm{Al}\left(\mathrm{CH}_{3}\right)_{2}$ groups (one singlet) indicates a $\mathrm{C}_{2 v}$-symmetric or averaged structure in solution $\left(C_{6} D_{6}\right)$. A cyclic voltammetry experiment of 1 reveals one reversible reduction event occurring at $-2.21 \mathrm{~V}$ and one irreversible oxidation at $0.38 \mathrm{~V}$ with respect to $\mathrm{Fc} / \mathrm{Fc}^{+}$in acetonitrile, Figure S5.

1 features a pronounced fluorescence both in solution and in the solid state, Figure 3, which, however, is significantly affected by the sample type. Hence, the photophysical properties of 1 in solution, as powder and as crystalline material were investigated by steady-state absorption and fluorescence spectroscopy, Table 1. The absorption spectrum of a solution of 1 in toluene reveals one narrow peak at $455 \mathrm{~nm}$. Quantum chemical investigations at the B3LYP10/def2SVP/SMD(toluene) level of theory allowed to assign this absorption feature to the excitation into the $S_{1}$ state of $\pi \pi^{*}$ nature (at $402 \mathrm{~nm}$ ), Figure 4a. The sample gives rise to a blue emission that is centered at $471 \mathrm{~nm}$, i.e., associated with a Stokes shift of $747 \mathrm{~cm}^{-1}$ and solutions of $\mathbf{1}$ in acetonitrile and dichloromethane give similar emission spectra with emission maxima at 471 and $472 \mathrm{~nm}$, respectively, Figure S6. The absence of pronounced solvatochromism indicates that the polarity of the solvent does not appreciably perturb the ground or excited state. This finding is in agreement with the computational data on the emission of 1 . Structural relaxation of the $S_{1}$ state from the Franck-Condon point yields the 
equilibrium of the formerly excited $\pi \pi^{*}$ state with merely slight structural rearrangement (see Table S5 for details). In consequence, an emission wavelength of $435 \mathrm{~nm}$ is predicted by quantum chemical calculations. Thus, the Stokes shift obtained at the time-dependent density functional theory (TDDFT) level is in good agreement with the experimental reference, i.e. $556 \mathrm{~cm}^{-1}$ versus $747 \mathrm{~cm}^{-1}$, and reflects the marginal structural rearrangement as well as the locally excited nature of the $\pi \pi^{*}$ transition and the absence of charge-transfer contributions, Figure $4 \mathrm{~b}$ ( $\pi \pi^{*}$ equilibrium). In addition to this radiative relaxation pathway, a non-radiative relaxation channel is in principle available but is inhibited by a barrier correlated to a stretch of the Al1-C17 bond - within the potential energy surface of the (adiabatic) $S_{1}$ state. Relaxation along this coordinate leads to a pronounced stabilization of the $S_{2} \sigma \pi^{*}$ state and, in consequence, to an elongation of the Al1-C17 bond from $1.9677 \AA$ within the Franck-Condon point (and $1.9699 \AA$ within the $\pi \pi^{*}$ equilibrium structure) to $2.1903 \AA$ in the equilibrium structure of the $\sigma \pi^{*}$ state. This stretch of the $\mathrm{Al}-\mathrm{CH}_{3}$ bond results from the electronic configuration within the excited $\left(\sigma \pi^{*}\right)$ state, with the respective $\sigma$-orbital being only singly occupied - reducing its bond order to 0.5 . Accordingly, the $\sigma \pi^{*}-S_{0}$ gap is lowered to approximately $1 \mathrm{eV}$ (Figure $4 \mathrm{~b}, \sigma \pi^{*}$ equilibrium structure) by the pronounced stabilization of the $\sigma \pi^{*}$ state and the destabilization of the electronic ground state upon elongation of the Al1-C17 bond. The population of this excited state relaxation pathway might impact the long-term photostability of $\mathbf{1}$ as it eventually leads to photodegradation by cleavage of the $\mathrm{Al} 1-\mathrm{C} 17$ bond as a result of the reduced bond order in the excited state.

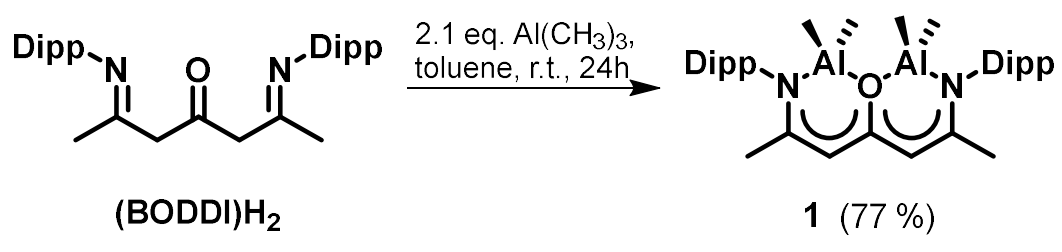

Scheme 1. Complex $\mathbf{1}$ is readily prepared from the protio-ligand (BODDI) $\mathbf{H}_{2}$. 


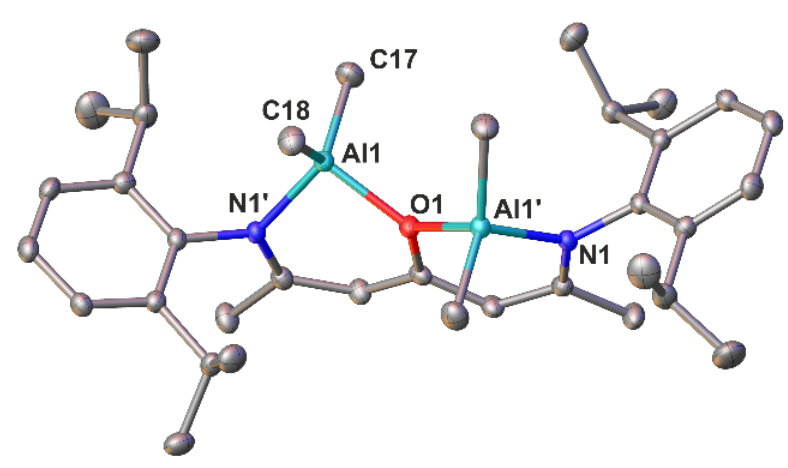

Figure 2. Molecular solid-state structure of 1 with hydrogen atoms omitted for clarity; symmetry operation for atoms marked with ' : 1-x, $+y, 3 / 2-z$. Selected bond lengths $[\AA ̊]$ and angles $\left[{ }^{\circ}\right]$ with calculated values [B3LYP10/def2svp/SMD(toluene)] in square brackets: Al1-N1' 1.9004(12) [1.927], Al1-O1 1.8938(8) [1.913], Al1-C17 1.9562(14) [1.968], Al1-C18 1.9575(16) [1.963], N1'-Al1-O1 95.28(5) [92.5], C17-Al1-C18 118.58(7) [122.3]. The computed structure is shown in Figure S4.

In contrast to the behavior in solution, the powder and the crystalline samples give rise to broad absorption bands with maxima at $438 \mathrm{~nm}$ and $457 \mathrm{~nm}$, respectively, and show a green emission although with differing emission spectra. The crystalline material features a single peak with an emission maximum at $528 \mathrm{~nm}$ (Stokes shift of $2942 \mathrm{~cm}^{-1}$ ) while in case of the powder, a maximum at $515 \mathrm{~nm}$ (Stokes shift of $3414 \mathrm{~cm}^{-1}$ ) is accompanied by two smaller peaks at 556 and $615 \mathrm{~nm}$. Such pronounced Stokes shifts clearly point to the formation of aggregates in the solid, which lead, in consequence, to the emerging of low-lying intermolecular charge-transfer states. ${ }^{16}$ This agrees well with the observed solid-state structure of $\mathbf{1}$, which features characteristics of J-aggregates. ${ }^{17}$ Aiming to obtain further insight, the quantum yield, as well as the fluorescence lifetime, have been investigated in toluene solution and in the solid state.

a)

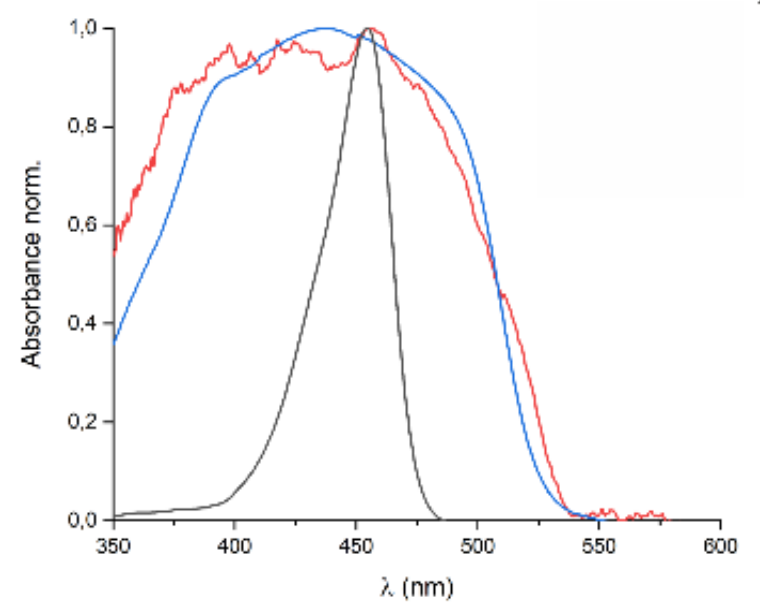

b)

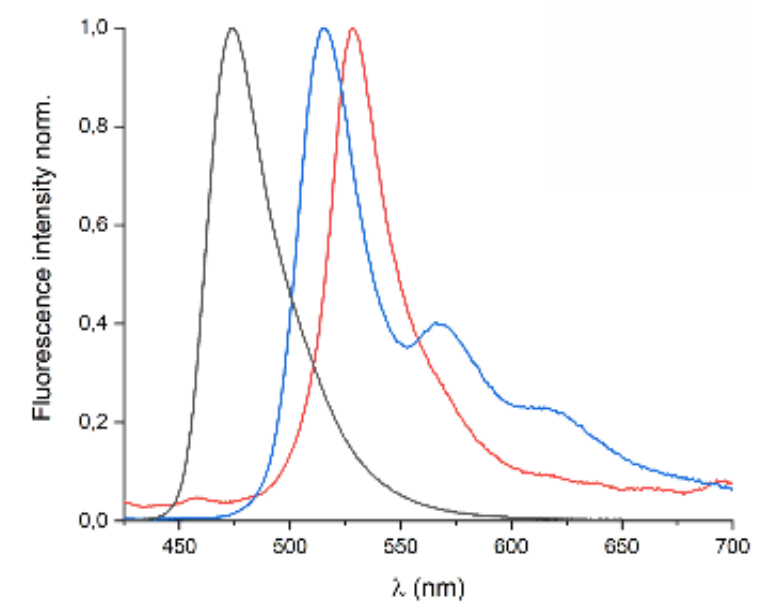

Figure 3. Normalized a) absorption and b) emission spectra of complex 1 as a single-crystal (red), powder sample (blue), and in toluene solution ( $1.40 \mu \mathrm{M}$, black). 


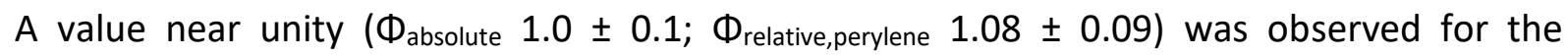
quantum yield of a toluene solution of 1 by absolute and relative measurements, which is, to the best of our knowledge, reported here for the first time. ${ }^{18}$ The high quantum yield is well reflected by the strong dipole-allowed nature of both the $S_{1} \leftarrow S_{0}$ as well as the $S_{1} \rightarrow S_{0}$ transitions associated with the initial absorption process as well as to emission as obtained by TDDFT. Furthermore, from the experimental findings, photodegradation via the $\sigma \pi^{*}$ channel, see Figure $4 b$, seems to be unlikely. The excited state has an intrinsic lifetime $\left(\tau_{0}\right)$ of $2.3 \mathrm{~ns}$, Figure $\mathrm{S} 7$, and a radiative decay rate $k_{\mathrm{r}}$ of $4.4 \times 10^{8} \mathrm{~s}^{-1}$.

Table 1. Selected experimental and computational photophysical properties of 1; see SI for experimental details.

\begin{tabular}{lcccc}
\hline & $\lambda_{\max }(\mathrm{nm})$ & $\lambda_{\mathrm{em}}(\mathrm{nm})$ & $\Phi_{\text {absolute }}$ & $\tau$ (ns) \\
\hline $\mathbf{1}$ (toluene) & 455 & 471 & $1.0 \pm 0.1$ & 2.3 \\
$\mathbf{1}$ (TDDFT) & 402 & 435 & - & - \\
$\mathbf{1}$ (powder) & 438 & 515 & $0.5 \pm 0.02$ & - \\
$\mathbf{1}$ (crystal) & 457 & 528 & $0.6 \pm 0.07$ & $1.8-2.5$ \\
$\mathbf{1}$ (fleece) & 327 and 387 & 490 & $0.9 \pm 0.04$ & $2.2-2.3$ \\
\hline
\end{tabular}

In the solid state quantum yields of 0.5 for the powder and 0.6 for the crystalline sample have been obtained. In a control experiment, mixtures of 1 and barium sulfate in various ratios were thoroughly ground and investigated (see SI for details), and extrapolation to infinite dilution gave a quantum yield of 0.5 . The reduced emission quantum yield in the solid samples can be related to aggregation-caused quenching $(A C Q)^{19}$ due to a reduced degree of intramolecular rotation particularly about the $\mathrm{C}-\mathrm{CH}_{3}$ bonds of the BODDI backbone. The crystals of 1 feature a distribution of excited state lifetime in the range of 1.8 to 2.5 ns, Figure S8, which has been established by means of fluorescence-lifetime imaging $(F L I M)^{20}$ and is in good agreement with the lifetime in solution. 


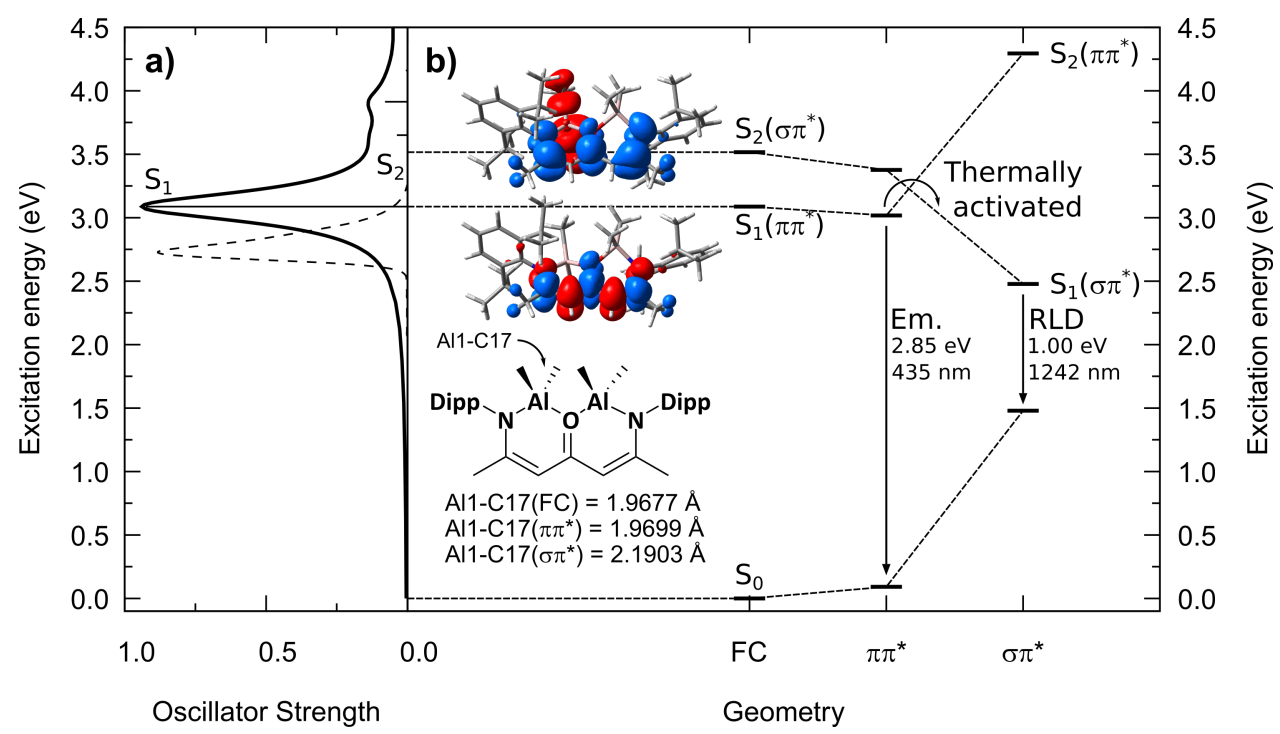

Figure 4. a) Experimental (in black, dashed) and simulated (in black, solid) UV-vis absorption spectrum of 1 in toluene; prominent electronic transitions are indicated. b) Energy levels of the singlet ground state (So) as well as of the excited states $S_{1}\left(\pi \pi^{*}\right.$, strongly dipole-allowed) and $S_{2}\left(\sigma \pi^{*}\right.$, dipole-forbidden) within their fully optimized equilibrium structures. Charge density differences (CDDs) indicate the electronic nature of $S_{1}\left(\pi \pi^{*}\right)$ and $S_{2}\left(\sigma \pi^{*}\right)$. Emission occurs from the $\pi \pi^{*}$ state. A radiation-less decay channel associated to photodegradation, i.e., cleavage of the Al1-C17 bond (see inset), might be accessible upon thermal activation and population of a $\sigma \pi^{*}$ state.

Electrospun luminescent nanofibers are of high value and have been used in a variety of photonic and optoelectronic applications. ${ }^{21}$ Hence, 1 was embedded in elastic nonwoven polymer fabrics by electrospinning of a tetrahydrofuran solution of 1 and polystyrene (1.8 and $16.2 \mathrm{wt} \%)$. The resulting flexible highly-fluorescent yellow-green fleece is easy to handle and cut, and can be stored in air for weeks without noticeable signs of decomposition. Fluorescence lifetime (FLIM) and scanning electron microscopy (SEM) images evidence the formation of beaded nanofibers with a smooth surface, Figure 5. Please note that bead formation has been reported before and was attributed to various parameters. ${ }^{22}$ As spinning of a control sample containing only polystyrene gave a colorless fabric showing significantly reduced bead formation, Figures S10a and S11, we assume that the addition of 1 lowers the surface tension of the solution, and, hence, the increased bead formation. The fibers feature two absorption maxima at 327 and $387 \mathrm{~nm}$, Figure S13, and upon excitation at $410 \mathrm{~nm}$ the material possesses an intense blue fluorescence $\left(\lambda_{\mathrm{em}}=490 \mathrm{~nm}\right)$ with a quantum yield of $0.9 \pm$ 0.04. Notably, interaction of $\mathbf{1}$ with the polystyrene matrix most likely causes the observed differing photophysical properties with respect to the solid state or solution samples. Finally, the excited state lifetime was again obtained by FLIM experiments, and although slight deviations between strains and beads could be recognized, the mean value of $2.3 \mathrm{~ns}$ is reminiscent of those data obtained for the crystal or a toluene solution of $\mathbf{1}$. 


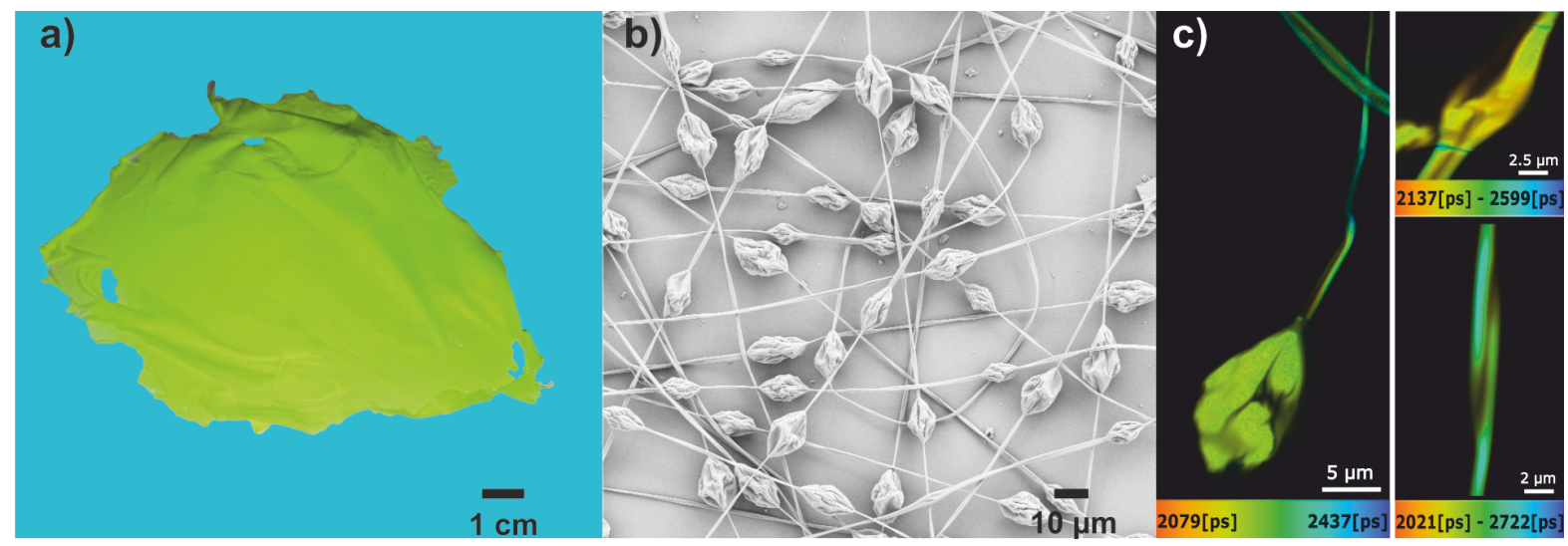

Figure 5. a) Photograph, b) SEM, and c) FLIM micrographs of a nonwoven polystyrene fabric containing 1.

\section{Conclusions}

In summary, we have discovered the novel dinuclear main-group metal complex $\mathbf{1}$ that is readily available and possesses strong fluorescence. Toluene solutions of 1 exhibit a nearunity quantum yield $\left(\Phi_{\text {absolute }} 1.0 \pm 0.1\right.$ ), which is unprecedented for aluminium(III) compounds, and caused by the strong dipole-allowed nature of both the absorption and the emission process. In the solid state, J-aggregation and aggregation-caused quenching give rise to lower but still high photoluminescence quantum yields of up to 0.6 . If the complex is embedded in electrospun non-woven fabrics, a highly fluorescent fleece with a quantum yield of $0.9 \pm 0.04$ is obtained. We are currently investigating routes towards other homoand heterodinuclear complexes based on the $\beta$-oxo- $\delta$-diimine ligand including those of $B(I I I)$, $\mathrm{Ga}(\mathrm{III})$, and In(III), aiming to adopt and improve the photophysical properties relevant for different optical applications. Furthermore, experiments to modify the ligand system with respect to the backbone and the terminal substituents are under way as well.

\section{Acknowledgements}

The project was financially supported by the Deutsche Forschungsgemeinschaft (DFG, KR4782/3-1 and 36454990-TRR234, CataLight, Z2, Germany's Excellence Strategy - EXC 2051 - Project-ID 390713860, project number 316213987 - SFB 1278 'PolyTarget', and INST 1757/25-1 FUGG), the Fonds der Chemischen Industrie and the Friedrich Schiller University Jena. We thank the Rechenzentrum of the Friedrich Schiller University Jena for the allocation of computer time, Fabian 
Seifert, and Raktim Baruah for helpful discussions, Florian C. Walter for assistance with the cyclic

voltammetry experiments, Angelika Henning for EDX and SEM investigations, Cindy Altmann for carrying out the electrospinning and Dr. Mathias Micheel for STREAK camera measurements.

\section{Notes and References}

1 (a) A. Loudet and K. Burgess, Chem. Rev., 2007, 107, 4891; (b) P. Kaur and K. Singh, J. Mater. Chem. C, 2019, 7, 11361; (c) J. C. Berrones-Reyes, C. C. Vidyasagar, B. M. Muñoz Flores and V. M. Jiménez-Pérez, J. Lumin., 2018, 195, 290.

2 (a) N. Boens, V. Leen and W. Dehaen, Chem. Soc. Rev., 2012, 41, 1130; (b) T. Kawashima, T. Agou and J. Yoshino, in Comprehensive Inorganic Chemistry II (Second Edition), ed. J. Reedijk and K. Poeppelmeier, Elsevier, Amsterdam, 2013, pp. 1053-1068; (c) Di Wu, A. C. Sedgwick, T. Gunnlaugsson, E. U. Akkaya, J. Yoon and T. D. James, Chem. Soc. Rev., 2017, 46, 7105.

3 (a) S. Wang, Coord. Chem. Rev., 2001, 215, 79; (b) X. Yang, G. Zhou and W.-Y. Wong, Chem. Soc. Rev., 2015, 44, 8484; (c) H. Xu, R. Chen, Q. Sun, W. Lai, Q. Su, W. Huang and X. Liu, Chem. Soc. Rev., 2014, 43, 3259; (d) Q. Wei, N. Fei, A. Islam, T. Lei, L. Hong, R. Peng, X. Fan, L. Chen, P. Gao and Z. Ge, Adv. Opt. Mater., 2018, 6, 1800512; (e) C. Bizzarri, E. Spuling, D. M. Knoll, D. Volz and S. Bräse, Coord. Chem. Rev., 2018, 373, 49.

4 N. R. Council, The Role of the Chemical Sciences in Finding Alternatives to Critical Resources. A Workshop Summary, The National Academies Press, Washington, DC, 2012.

5 (a) L. J. Patalag, L. P. Ho, P. G. Jones and D. B. Werz, J. Am. Chem. Soc., 2017, 139, 15104; (b) Z. Liu, Z. Jiang, M. Yan and X. Wang, Front. Chem., 2019, 7, 712; (c) L. J. Patalag, J. Hoche, M. Holzapfel, A. Schmiedel, R. Mitric, C. Lambert and D. B. Werz, J. Am. Chem. Soc., 2021, 143, 7414; (d) P. Shrestha, K. C. Dissanayake, E. J. Gehrmann, C. S. Wijesooriya, A. Mukhopadhyay, E. A. Smith and A. H. Winter, J. Am. Chem. Soc., 2020, 142, 15505; (e) A. Atilgan, M. M. Cetin, J. Yu, Y. Beldjoudi, J. Liu, C. L. Stern, F. M. Cetin, T. Islamoglu, O. K. Farha, P. Deria, J. F. Stoddart and J. T. Hupp, J. Am. Chem. Soc., 2020, 142, 18554; (f) E. Y. Zhou, H. J. Knox, C. Liu, W. Zhao and J. Chan, J. Am. Chem. Soc., 2019, 141, 17601.

6 (a) C. W. Tang and S. A. VanSlyke, Appl. Phys. Lett., 1987, 51, 913; (b) D. Z. Garbuzov, V. Bulović, P. E. Burrows and S. R. Forrest, Chem. Phys. Lett., 1996, 249, 433.

7 (a) C. H. Chen and J. Shi, Coord. Chem. Rev., 1998, 171, 161; (b) L. S. Sapochak, A. Padmaperuma, N. Washton, F. Endrino, G. T. Schmett, J. Marshall, D. Fogarty, P. E. Burrows and S. R. Forrest, J. Am. Chem. Soc., 2001, 123, 6300; (c) V. A. Montes, R. Pohl, J. Shinar and P. Anzenbacher, Chem. Eur. J., 2006, 12, 4523; (d) M. Albrecht, M. Fiege and O. Osetska, Coord. Chem. Rev., 2008, 252, 812; (e) D. Singh, V. Nishal, S. Bhagwan, R. K. Saini and I. Singh, Mater. Des., 2018, 156, 215.

8 (a) M. Saikawa, M. Daicho, T. Nakamura, J. Uchida, M. Yamamura and T. Nabeshima, Chem. Commun., 2016, 52, 4014; (b) C. Ikeda, S. Ueda and T. Nabeshima, Chem. Commun., 2009, 2544; (c) S. Bestgen, C. Schoo, B. L. Neumeier, T. J. Feuerstein, C. Zovko, R. Köppe, C. Feldmann and P. W. Roesky, Angew. Chem. Int. Ed., 2018, 57, 14265; (d) J. Li, P. Wu, W. Jiang, B. Li, B. Wang, H. Zhu and H. W. Roesky, Angew. Chem. Int. Ed., 2020, 59, 10027; (e) T. Ono, K. Ishihama, A. Taema, T. Harada, K. Furusho, M. Hasegawa, Y. Nojima, M. Abe and Y. Hisaeda, Angew. Chem. Int. Ed., 2021, 60, 2614; (f) K. Nakao, H. Sasabe, Y. Shibuya, A. Matsunaga, H. Katagiri and J. Kido, Angew. Chem. Int. Ed., 2021, 60, 6036.

9 S. Katsuta, Chem. Lett., 1994, 23, 1239.

10 X.-F. Zhang and J. Zhu, J. Lumin., 2019, 205, 148.

11 W. Wan, M. S. Silva, C. D. McMillen, S. E. Creager and R. C. Smith, J. Am. Chem. Soc., 2019, 141, 8703.

12 G. Li, D. Zhu, X. Wang, Z. Su and M. R. Bryce, Chem. Soc. Rev., 2020, 49, 765. 
13 (a) S. D. Allen, D. R. Moore, E. B. Lobkovsky and G. W. Coates, J. Organomet. Chem., 2003, 683, 137; (b) H.-C. Chiu, A. J. Pearce, P. L. Dunn, C. J. Cramer and I. A. Tonks, Organometallics, 2016, 35, 2076.

14 (a) S. Li, M. Wang, B. Liu, L. Li, J. Cheng, C. Wu, D. Liu, J. Liu and D. Cui, Chem. Eur. J., 2014, 20, 15493; (b) F. Yan, S. Li, L. Li, W. Zhang, D. Cui, M. Wang and Y. Dou, Eur. J. Inorg. Chem., 2019, 2019, 2277.

15 (a) J. Lewiński, I. Justyniak, J. Zachara and E. Tratkiewicz, Organometallics, 2003, 22, 4151; (b) V. C. Gibson, D. Nienhuis, C. Redshaw, A. J. P. White and D. J. Williams, Dalton Trans., 2004, 1761;

(c) A. Arbaoui, C. Redshaw and D. L. Hughes, Chem. Commun., 2008, 4717; (d) J. Liu, N. Iwasa and K. Nomura, Dalton Trans., 2008, 3978.

16 (a) A. Dreuw, J. Plötner, L. Lorenz, J. Wachtveitl, J. E. Djanhan, J. Brüning, T. Metz, M. Bolte and M. U. Schmidt, Angew. Chem. Int. Ed., 2005, 44, 7783; (b) S. H. Habenicht, S. Kupfer, J. Nowotny, S. Schramm, D. Weiß, R. Beckert and H. Görls, Dyes Pigm., 2018, 149, 644.

17 F. Würthner, T. E. Kaiser and C. R. Saha-Möller, Angew. Chem. Int. Ed., 2011, 50, 3376.

18 G. A. Crosby and J. N. Demas, J. Phys. Chem., 1971, 75, 991.

19 (a) J. R. Lakowicz, ed., Principles of Fluorescence Spectroscopy, Springer US, Boston, MA, 2006; (b) D. Zhai, W. Xu, L. Zhang and Y.-T. Chang, Chem. Soc. Rev., 2014, 43, 2402; (c) X. Ma, R. Sun, J. Cheng, J. Liu, F. Gou, H. Xiang and X. Zhou, J. Chem. Educ., 2016, 93, 345; (d) Q. Li and Z. Li, Adv. Sci., 2017, 4, 1600484; (e) J. Qi, X. Hu, X. Dong, Y. Lu, H. Lu, W. Zhao and W. Wu, Adv. Drug Deliv. Rev., 2019, 143, 206.

20 R. Datta, T. M. Heaster, J. T. Sharick, A. A. Gillette and M. C. Skala, J. Biomed. Opt., 2020, $25,1$.

21 (a) A. Camposeo, L. Persano and D. Pisignano, Macromol. Mater. Eng., 2013, 298, 487; (b) A. Camposeo, M. Moffa and L. Persano, in Electrospinning for High Performance Sensors, ed. A. Macagnano, E. Zampetti and E. Kny, Springer International Publishing, Cham, 2015, pp. 129-155; (c) G. George and Z. Luo, Curr. Nanosci., 2020, 16, 321.

22 (a) H. Fong, I. Chun and D.H. Reneker, Polymer, 1999, 40, 4585; (b) Y. Liu, J.-H. He, J.-Y. Yu and H.M. Zeng, Polym. Int., 2008, 57, 632. 